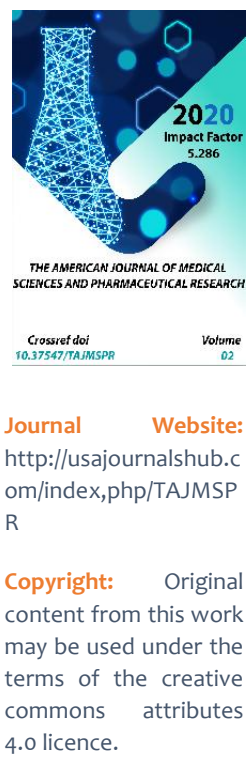

\title{
Climate Change And Human Health
}

\author{
Axrorova Malika Shavkatovna \\ Samarkand State Medical Institute Assistant Of The Department Of Pediatric Dentistry, \\ Samarkand City, Uzbekistan \\ Arzikulova Munisa Shuhratovna \\ Samarkand State Medical Institute Assistant Of The Department Of Pediatric Dentistry, \\ Samarkand City, Uzbekistan \\ Rahimberdiev Rustam Abdunosirovich \\ Samarkand State Medical Institute, Head Of The Department Of Pediatric Dentistry, \\ Samarkand City, Uzbekistan \\ Shukurov Sherzod Shukhratovich \\ Samarkand State Medical Institute Assistant Of The Department Of Pediatric Dentistry, \\ Samarkand City, Uzbekistan
}

\section{ABSTRACT}

This article is prepared for climate change and factors that have a strong impact on human health. This article mainly provides detailed views and comments on the required level of body temperature for human health and its place today.

\section{KEYWORDS}

Global warming, malnutrition, heat wave, respiratory illnesses, pollen.

\section{INTRODUCTION}

The effects of global warming include its effects on human health. The observed and projected increased frequency and severity of climate related impacts will further exacerbate the effects on human health. This article describes some of those effects on individuals and populations.

Impact of excess heat on the human body
The human body requires evaporative cooling to prevent overheating, even with a low activity level. With excessive ambient heat and humidity, adequate evaporative cooling does not take place. Human thermoregulatory capacity is exceeded. A sustained wet-bulb temperature or Wet-bulb globe temperature exceeding about $35^{\circ} \mathrm{C}\left(95^{\circ} \mathrm{F}\right)$ can be fatal. Human response to heat stress can be 
hyperthermia, heat stroke and other harmful effects. Heat illness can relate to many of the organs and systems including: brain, heart, kidneys, liver, etc.

\section{Impact on infectious diseases}

Further information: Climate change and infectious diseases

Warming oceans and a changing climate are resulting in extreme weather patterns which have brought about an increase of infectious diseases-both new and re-emerging. These extreme weather patterns are creating extended rainy seasons in some areas, and extended periods of drought in others,[13] as well as introducing new climates to different regions. These extended seasons are creating climates that are able to sustain vectors for longer periods of time, allowing them to multiply rapidly, and also creating climates that are allowing the introduction and survival of new vectors.

In 2016 the United Nations Environment Programmer published a report called: "UNEP FRONTIERS 2016 REPORT". In this report, the second chapter was dedicated to Zoonotic diseases, e.g., diseases that pass from animals to humans. In this chapter was written that deforestation, climate change, and livestock agriculture are among the main causes that increase the risk of such diseases. It was mentioned that every 4 months a new disease is discovered in humans. It was said that outbreaks that already happened (as of 2016) led to loss of lives and financial losses of billions dollars and if future diseases will turn into pandemics it will cost trillions of dollars.

\section{Impact of warmer and wetter climates}

Mosquito-borne diseases are probably the greatest threat to humans as they include malaria, elephantiasis, Rift Valley fever, yellow fever, and dengue fever. Studies are showing higher prevalence of these diseases in areas that have experienced extreme flooding and drought. Flooding creates more standing water for mosquitoes to breed; as well, shown that these vectors are able to feed more and grow faster in warmer climates. As the climate warms over the oceans and coastal regions, warmer temperatures are also creeping up to higher elevations allowing mosquitoes to survive in areas they had never been able to before. As the climate continues to warm there is a risk that malaria will make a return to the developed world. Ticks are also thriving in the warmer temperatures allowing them to feed and grow at a faster rate. The black legged tick, a carrier of Lyme disease, when not feeding, spends its time burrowed in soil absorbing moisture. Ticks die when the climate either becomes too cold or when the climate becomes too dry, causing the ticks to dry out. The natural environmental controls that used to keep the tick populations in check are disappearing, and warmer and wetter climates are allowing the ticks to breed and grow at an alarming rate, resulting in an increase in Lyme diseases both in existing areas and in areas where it has not been seen before.

\section{Impact of warmer freshwater}

Warmer freshwater is increasing the presence of the amoeba Nigeria fowler, in freshwater and the parasite Cryptosporidium in pools, and both can cause a severe disease. Therefore, climate change will probably raise the number of those pathogens. According to a letter of health officials, warning from the Nigeria fowler: "Infections usually occur when temperatures increase for prolonged periods 
of time, which results in higher water temperatures and lower water levels,"

\section{Air pollution}

The pollution of air by nitrogen dioxide (NO2), ozone ( $\left.\mathrm{O}_{3}\right)$ and particulate matter (PM) is associated with increased all-cause and cardiovascular mortality and morbidity, and exposure to elevated concentrations of ozone over shorter periods of time is associated with increased respiratory mortality and morbidity. Warmer weather, more frequent heat waves, changes in rainfall and altered volatile organic compound concentrations may increase future $\mathrm{O}_{3}$ and $\mathrm{PM}$ concentrations. The evidence from recent heat waves such as that of 2003 suggests that in the UK a third of the excess mortality experienced during a heat wave may be caused by exposure to elevated concentrations of $\mathrm{O}_{3}$ and $\mathrm{PM} 10$.

$\mathrm{NO}_{2}$ concentrations are particularly high in cities near major transport corridors where socio-economically deprived and poor people and ethnic minorities are over-represented. If PM concentrations have similar distribution patterns then their increase in changing climate would increase the exposure of the same people to the adverse health outcomes of $\mathrm{PM}$. The situation with $\mathrm{O}_{3}$ is more complex as high urban $\mathrm{NO}$ and $\mathrm{NO} 2$ concentrations inhibit the formation of $\mathrm{O}_{3}$. However, high $\mathrm{O}_{3}$ concentrations can prevail in cities in future if public policies do succeed in bringing down urban nitrogen oxide emissions.

Social deprivation and age pre-dispose people for cardiovascular illnesses, which in turn compounds the effects of elevated $\mathrm{O}_{3}$ and PM concentrations on their health. In 2008, the most deprived quintile in the UK experienced $50 \%$ higher cardiovascular disease mortality than the least deprived quintile [8]. Women in routine jobs experience five times higher cardiovascular disease mortality than women in managerial and professional jobs. These differences in cardiovascular mortality risk and sensitivity to $\mathrm{O}_{3}$ and $\mathrm{PM}$ pollution emerge from differences in the levels of deprivation, lifestyles, health literacy, access to health services, and environmental exposure. Social deprivation and ethnicity can also constrain adaptive capacity by limiting ability to relocate and to take other measures to avoid exposure or to reduce sensitivity.

\section{Pollen and human health}

Pollen is one key factor in asthma, which can trigger inflammation of airways, coughing and breathing difficulties among people whose immune systems have become hypersensitive to triggers like pollen [29]. Birch and related trees are a key source of pollen in the early pollen season, replaced by grasses later in the season: warming will prolong pollen season and can lead to appearance of new sources of pollen when plant species mix changes due to warming. High pollen levels occur during calm and warm high-pressure systems, and rain and westerly winds lower pollen levels because of wet deposition. Events such as thunderstorms can transform pollen into biological aerosols containing allergens and leading to asthma outbreaks. Therefore, global warming and associated increased frequency and intensity of extreme weather events can aggravate the human health impacts of pollen.

While exposure to pollen may be greater in rural areas, trees and weeds lead to pollen exposure in urban areas as well. Asthma has nearly $10 \%$ prevalence in the UK population, but among 6-7 year olds its prevalence is over $20 \%$. Asthma is more common among lower socio-economic status people and among Afro-Caribbean's but the role of pollen in the incidence of asthma is not well understood. While asthma is more common in the young, a 
study of asthma mortality in the United States between 2010 and 2012 indicates that older people with asthma have 5 times higher mortality risk from asthma than younger people. Older people also more frequently experienced other adverse outcomes due to acute asthma in the United States [30]. Other medical conditions such as cardiovascular disease are common co-morbidities of asthma in older people.

\section{Food borne diseases}

\section{MATERIALS AND METHODS}

Prevalence and impacts of food safety related pathogens campylobacter and salmonella is likely to be affected by climate change. Campylobacter cases have increased and in 2012 they led to 18,000 hospitalizations, 80 deaths and economic losses of $£ 600$ million per annum in England and Wales. However, the projections for future campylobacter cases are uncertain because different drivers influence cases occurring via dietary and environmental pathways. Salmonella cases have decreased: 9000-10,000 salmonella cases have been reported to the Health Protection Agency and its successor Public Health England in recent years. These have led to 8500 hospital admissions, 199 deaths and economic losses of $£ 39$ million per annum in England and Wales. Climate change may countervail the reduction in salmonella cases brought about by improved food hygiene over the past two decades.

\section{CONCLUSION}

In terms of exposure, campylobacter is more prevalent in rural areas and in areas with less social deprivation. It is also more common in infants than in adults and older age groups. Poultry is the most common dietary source of campylobacter. The geographic prevalence of salmonella has not been studied in the UK. Salmonella is typically contracted from raw or undercooked eggs or poultry and it is most common in small children. The elderly and households with small children are the two groups for whom food safety will be a particular problem because of the greater sensitivity of the infants and elderly. Their situation can be exacerbated by low incomes, isolation and other factors that reduce adaptive capacity.

\section{REFERENCE}

1. Melillo, J. M., T. (T. C. ) Richmond, and G. W. Yohe, eds., 2014: Climate Change Impacts in the United States: The Third National Climate Assessment. U.S. Global Change Research Program, $841 \mathrm{pp}$. doi:10.7930/JoZ31WJ2 | Detail

2. NOAA, cited 2010: Weather Fatalities. National Oceanic and Atmospheric Administration. URL | Detail

3. Schwartz, J. D., and others, 2015: Projections of temperature-attributable premature deaths in 209 U.S. cities using a cluster-based Poisson approach. Environmental Health, 14. doi:10.1186/s12940-015-0071-2 | Detail 